\title{
EFFECT OF SOIL SCARIFICATION ON NATURAL REGENERATION OF MATURE SCOTS PINE (Pinus sylvestris) STANDS IN GREECE
}

\author{
GRIGORIADIS N. ${ }^{1, *}$ \\ SPYROGLOU G. ${ }^{1}$ \\ GRIGORIADIS S. ${ }^{2}$ \\ KLAPANIS P. ${ }^{3}$
}

Received: 08/01/2014

Accepted: $19 / 06 / 2014$

Available online: $20 / 06 / 2014$

\author{
${ }^{1}$ Hellenic Agricultural Organization - Demeter, Forest Research Institute \\ Loutra Thermis 57006 Thessaloniki, Greece \\ ${ }^{2}$ Forester Environmentalist, Papanikolaou 2, 54352, Thessaloniki \\ ${ }^{3}$ Forest Directorate of Pieria, Epeirou 10, 60100 Katerini
}

\begin{abstract}
The natural regeneration of Scots pine stands at the Sarakatsana location in the Pieria Mountains improved considerably after the removal of the dense ground vegetation followed mechanical soil scarification. The experimental design consisted of replications on scarified and non-scarified soil. The results four years after the experiment was set up showed that regeneration reached 59 seedlings $\mathrm{m}-2$ in scarified and 7 seedlings $\mathrm{m}-2$ in non-scarified soil. Soil scarification seems to have had a positive effect on the emergence and survival of naturally regenerated Scots pine. The negligible number of dead seedlings in the first two measurements could be due to the favourable site and/or good climatic conditions. Although the mother stand appears to be in a critical condition due to age and increased necrosis as a result of fungal attacks, there is still considerable potential for regeneration in terms of fructification and seed production. The study findings indicate that there can be new growth of Scots pine forest with the shelterwood method of natural regeneration in combination with soil scarification.
\end{abstract}

Keywords: Regeneration, Silviculture, Scarification, Scots Pine, Pieria Mt.

\section{Introduction}

Pure and mixed stands of Scots pine (Pinus sylvestris L.) occupy an area of 20.944 ha (Ministry of Agriculture, 1992). As a high altitude species, Scots pine usually forms the tree line in the Greek mountain ranges of Pieria, Vermio, Orvilos, Lailias and Rhodope which constitute the species' Southernmost limits of European distribution (Athanasiadis, 1986; Strid and Tan, 1997). Even though in Greece Scots pine is limited to specific areas, it is of considerable ecological and economic significance, particularly within the context of the global warming phenomenon with its adverse effect on forests (Koski, 1991; Loarie et al., 2009). Climate change make the survival of Scots pine in these areas uncertain because there is no possibility of its shifting to an even higher altitude (Loarie et al., 2009; Mason and Alías, 2000, Bergengren et al., 2011; Groffman et al., 2012; Grace et al., 2002; Rebetez and Dobbertin, 2004; Kullman, 2007).

Many previous studies have shown significant relationships between the succession of natural regeneration and site factors as well as the mother stand (Tegelmark, 1998; Hille and Ouden, 2004; Hallikainen et al., 2007). More specifically, soil scarification has proved to be particularly favourable for other species of the boreal coniferous zone, such as spruce, beech and birch (Huss and Burshcel, 1972; Dohrenbusch, 1997). In their study on the effects of forest fires on Scots pine regeneration, Kuuluvainen and Rouvinen's (2000), findings showed there was significant variation in the understorey tree 
population in terms of abundance, quality and spatial pattern. They found that the time factor since the last fire plays a restrictive role on the establishment of new understorey trees. Rodrigo et al. (2004) found that Scots pine forests do not follow the direct regeneration pattern after fire but change to other situations mainly because the trees cannot keep their cones closed for years. This partial failure of direct regeneration in combination with climate change needs serious consideration for the regeneration of the Mediterranean Scots pine ecosystems after fire.

Natural regeneration is also affected by ground vegetation, which hinders, firstly, seedling roots coming into contact with moist soil and secondly, their access to nutrients (Béland et al., 2000). In addition, Karlsson and Örlander, (2000) found in their study that the establishment of Scots pine regeneration is significantly affected when soil scarification occurs just before there is a rich seed fall. Hannerz et al., (2002) report that soil scarification carried out in the spring, no later than mid-May creates a good seed bed for that year's seeds. Castro et al., (2002) have analyzed the role of the herbaceaous layer as a barrier mechanism that impedes the establishment of woody Scots pine seedlings, rather than acting competively through biotic interactions. This occurs particularly in Mediterranean environments where, herbaceous ground vegetation loses most of its moisture before the achievement of seedling emergence. Scots pine distribution and regeneration in Mediterranean region is different to that of northern Europe. This distinction is determined by differences in climatic conditions and more specifically drought, which directly affects seedlings establishment (Castro et al., 2004).

Over the last thirty years fungal attacks have caused dieback of Scots pine in the Pieria mountains (Diamandis and de Kam, 1986; Diamandis and Perlerou, 2003). The increasing necrotic phenomena along with the inability of old growth stands to regenerate naturally are of major concern the local Forest Service.

The aims of the present study were twofold: (1) to determine whether the treatment of soil scarification has a positive effect on natural regeneration in comparison to non-scarified soil in old and low density Scots pine stands; and (2) whether the spatial position of the disseminated seeds affects the emergence and the survival of the natural regeneration os Scot pine in the Pieria Mountains.

\section{Material and methods}

\subsection{Experimental site and treatments}

Our study site was in the Pieria Mountains at a location known as Sarakatsana (Figure 1), which is part of the state owned forest $\left(40^{\circ} 16,25^{\prime} \mathrm{N}, 22^{\circ} 12,51^{\prime} \mathrm{E}\right.$, alt. $1700 \mathrm{~m}$ a.s.l, slope $20 \%$ and the North aspect).

The mother stand had: mean breast height diameter $(\mathrm{dbh}) 71.3 \mathrm{~cm}$, mean height $22.7 \mathrm{~m}$, mean height to the base of live crown $8.5 \mathrm{~m}$ and mean green crown length $14.3 \mathrm{~m}$. The number of stems were 60 per ha, the basal area was $29.2 \mathrm{~m}^{2} \mathrm{ha}^{-1}$ and the under bark stocking volume was $233.04 \mathrm{~m}^{3} \mathrm{ha}^{-1}$. From the stumps of recently cut neighbouring trees, the age of the stand was estimated to be around 130 years. Ground cover degree was found at 0.17 and the canopy closure at 0.20 . The mean projection of the crowns of the mother stems was $27.9 \mathrm{~m}^{2}$. The cover of the herbaceous layer in the non-scarified soil was $98 \%$ while one year after scarification the respective ground cover was $15 \%$. The species of the herbaceous vegetation in order of importance for each treatment were as follows:

Scarified soil: Pinus sylvestris (5\%), Festuca nigrescen sssp. nigrescens Lam. (4\%), Deschampsia flexuosa L. $(4 \%)$ and other species with a smaller $(<1 \%)$ participation.

Non-scarified soil: Vaccinium myrtillus L. (30\%), Deschampsia flexuosa (20\%), Festuca nigrescens ssp. nigrescens (15\%), Luzula luzuloides (L.) (5\%), Myosotis sylvatica Ehrh. (5\%), Cardus sp. (5\%), Hyeracium sp. (2\%), Campanula sparsa Friv. (2\%) and other species with a smaller $(<1 \%)$ participation.

Climatically, the area belongs to the mountainous zone with conditions that are similar to those of central Europe, i.e. there is a transition from Mediterranean to sub Mediterranean -temperate continental climate. Geologically, the area belongs to the Serbo-Macedonian zone, occupied by siliceous -Cristal schist rocks (gneiss) and soils of low productivity (Papamichos, 1979). 
The experiment is organized in two treatments (scarified and non-scarified soil). Every treatment on the soil had dimensions of $10 \times 40 \mathrm{~m}$ with three replications (Figure 2).

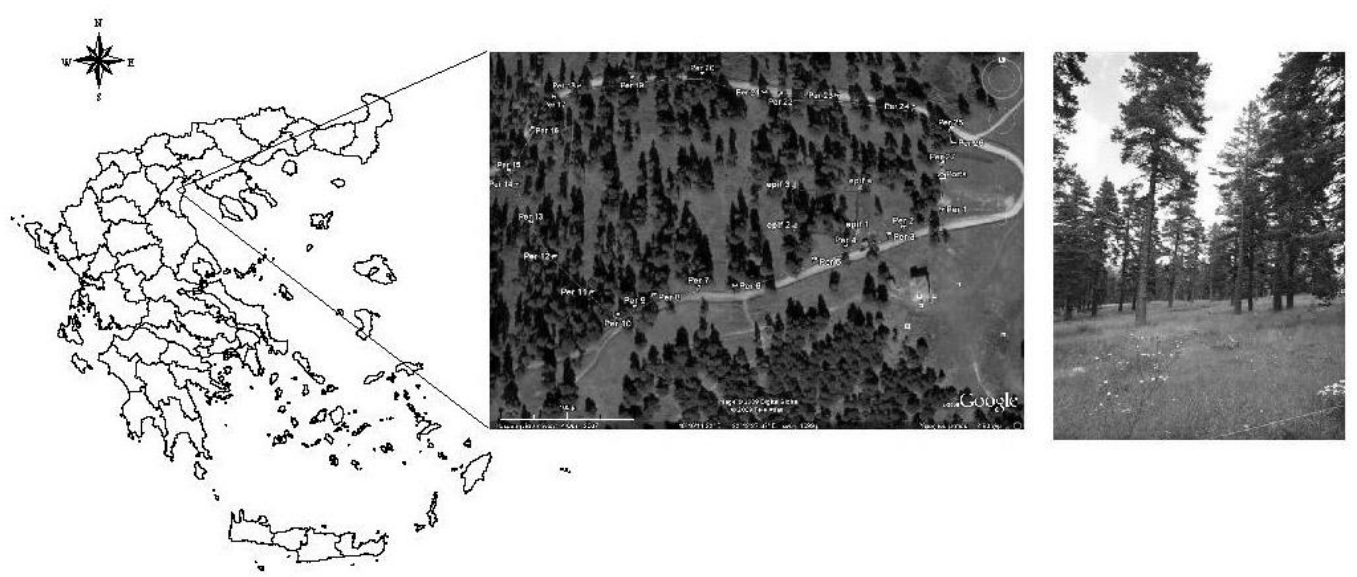

Figure 1. Map of the experimental plot of Scots pine at Pieria Mt. (location Sarakatsana).

Scarification was carried out in the autumn 2008 and comprised the mechanical removal of the surface organic cover, i.e. revealing the mineral soil parallel with the contours. The scarificator, a small bulldozer Caterpillar D7, created strips $2 \mathrm{~m}$ wide and $15 \mathrm{~cm}$ deep. An experimental area of 6.6 ha was fenced off with wire mesh to provide protection against livestock grazing.

\begin{tabular}{|cccccccccccccc|}
\hline 0 & 0 & 0 & 0 & 0 & 0 & 0 & 0 & 0 & 0 & 0 & 0 & 0 & 0 \\
\hdashline 0 & 0 & 0 & 0 & 0 & 0 & 0 & 0 & 0 & 0 & 0 & 0 & 0 & 0 \\
\hline 0 & -0 & 0 & 0 & 0 & 0 & 0 & 0 & 0 & 0 & 0 & 0 & 0 & 0 \\
\hline 0 & 0 & 0 & 0 & 0 & 0 & 0 & 0 & 0 & 0 & 0 & 0 & 0 & 0 \\
\hline 0 & 0 & 0 & 0 & 0 & 0 & 0 & 0 & 0 & 0 & 0 & 0 & 0 & 0 \\
\hline 0 & $\cdot 0$ & 0 & 0 & 0 & 0 & 0 & 0 & 0 & 0 & 0 & 0 & 0 & 0 \\
\hline
\end{tabular}

Figure 2. Layout of treatment plots and traps, black circles indicate seed traps $1 \mathrm{~m}^{2}$, white circles indicate sample plots where seedlings were measured $1 \mathrm{~m}^{2}$, dashed lines separate treatments (scarified/non-scarified soil) full bold horizontal lines separate repetitions.

\subsection{Weather data}

Meteorological data such as air temperature, precipitation and relative humidity were obtained from an electronic weather station that had been operated some years prior to the experiment $500 \mathrm{~m}$ Northeast from the study area (alt. $1670 \mathrm{~m}$ a.s.l, http://meddman.agro. auth.gr/index.php?stationID=7).

Temperature and precipitation were used to construct the climatic diagram for the vegetative periods 2009 - 2011 (Figure 3). The mean monthly precipitation in the vegetation period exhibits variations. Over the two year period, there was a sharp reduction in precipitation from $816 \mathrm{~mm}$ in 2009 to just over half $(435 \mathrm{~mm})$ in 2011. Figure 3 also shows that while there was no hot and dry period in 2009 but there was one for approximately one month in both 2011 and 2012, a phenomenon that is not normally 
observed at such altitudes or in such ecosystems. The 2011 hot and dry period was succeeded the autumn season with monthly rainfalls that did not exceed $63 \mathrm{~mm}$ however, in 2009 and 2010, respective rainfall exceeded $270 \mathrm{~mm}$ each year. The same decreasing trend was recorded for mean monthly relative humidity in the vegetation period where it gradually decreased from $77.1 \%$ in 2009 to $74.1 \%$ and to $64.4 \%$ in 2011 and 2012.

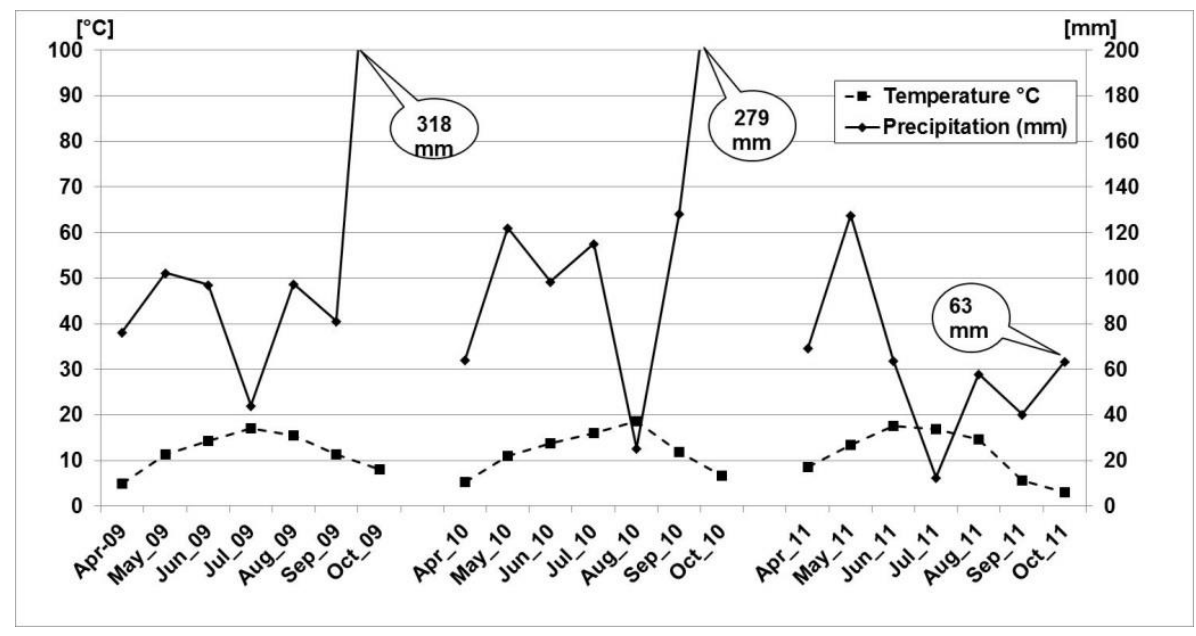

Figure 3. Climatic diagram of GAUSSEN - WALTER for the first (three) vegetation periods after scarification at the Sarakatsana location on the Pieria Mountain, $1700 \mathrm{~m}$ a.s.l (source: http://meddman.agro. auth.gr/index.php?stationID=7)

\subsection{Natural regeneration data}

Within each treatment plot, 16 circular sample plots were placed out systematically and their centers were marked with poles (Figure 2). The diameter of each plot was $1.128 \mathrm{~m}$ (area $1 \mathrm{~m}^{2}$ ). The number of live and dead seedlings was measured each summer following scarification (2009) until the end of 2012.

Seed traps of $1 \mathrm{~m}^{2}$ each were set along three replications ( 3 traps for each replication) (Figure 2). The seed fall has been measured every year between 2010 and 2013.

\subsection{Statistical analysis}

Mixed ANOVA (GLM) with repeated measures was used to analyze and compare differences between groups (soil treatments, replications) and differences within groups (time of measurement) $p=0,05$ was chosen as the cut-off level for statistical significance (Page et. al., 2003). The ANOVA general model was:

$Y_{i j}=\mu+b_{i}+c i+w_{j}+\varepsilon_{i j}$

where $Y_{i j}=$ observed quantity of seedlings, for group $j$ in block $i, \mu=$ general mean, $b_{i}=$ effect of soil treatment $\mathrm{i}, \mathrm{c}_{\mathrm{i}}=$ effect of repetition $\mathrm{i}, \mathrm{w}_{\mathrm{j}}=$ effect of time $\mathrm{j}$, and $\varepsilon_{\mathrm{ij}}=$ random error. Results of the ANOVA are shown as $[F(d f 1 ; d f 2)=$ value, $\mathrm{p}=$ value when $p<0.05]$, where $\mathrm{df1}=$ degrees of freedom for groups and df2=degrees of freedom for random variation. All statistical analyses were done with SPSS, Release 17.

\section{Results}

\subsection{Regeneration}

\subsubsection{Seed production}

After the seedtraps were set up, a total of eight seedfall collections were caried out - two for each year (Table 1). The seedfall for 2011 was satisfactory in comparison to the other years. The 2011 germination test of seedfall showed that the germination ability was $29.6 \%$, empty seeds $57.2 \%$ and dead seeds $13.2 \%$. For 2013 the germination ability of the seeds was $66.3 \%, 29.1 \%$ were empty and $4.1 \%$ dead. 
Table 1. Seed production for each seed trap in seeds $\mathrm{m}^{-2}$

\begin{tabular}{ccccccccccc}
\hline & 1 & 2 & 3 & 4 & 5 & 6 & 7 & 8 & 9 & mean \\
\hline 2010 & 40 & 79 & 33 & 26 & 49 & 56 & 105 & 52 & 87 & $\mathbf{5 9}$ \\
\hline 2011 & 107 & 135 & 90 & 80 & 100 & 109 & 211 & 110 & 94 & $\mathbf{1 1 5}$ \\
\hline 2012 & 11 & 1 & 7 & 2 & 1 & 4 & 0 & 3 & 4 & $\mathbf{4}$ \\
\hline 2013 & 48 & 55 & 42 & 39 & 38 & 47 & 112 & 39 & 44 & $\mathbf{5 2}$ \\
\hline
\end{tabular}

\subsubsection{Live seedlings}

The analysis showed that the number of live seedlings in scarified soil follows a different evolution pattern in time compared to those in non-scarified soil. In the first year (2009), there was a mean value of 28 seedlings $\mathrm{m}^{-2}$ in scarified and 10 seedlings $\mathrm{m}^{-2}$ in non-scarified soil. In the second year (2010) the mean number of scots pine seedlings increased from 28 to 60 seedlings $\mathrm{m}^{-2}$ in scarified soil but decreased from 10 to 6 seedlings $\mathrm{m}^{-2}$ in non-scarified soil. In the third year (2011), the number of seedlings remained at the same level (61) and in the fourth year (2012) the mean decreased from 61 to 41 seedlings $\mathrm{m}^{-2}$ in scarified soil, while in non-scarified soil from 6 seedlings $\mathrm{m}^{-2}$ it continued to decrease to 3 seedlings $\mathrm{m}^{-2}$. (Figure 4). There was a statistically significant main effect of soil treatment in Scots pine live seedlings $[F(1 ; 69)=189.06 ; p<0.001]$. There was also a significant interaction effect between soil treatment and time of measurement $[F(2.53 ; 174.84)=40.28 ; p<0.001]$ and graphically depicted by the non-parallel curves in Figure 4. The values for the $F$ criterion for the time effect but also for the time $x$ soil treatment interaction resulted from the correction of the degrees of freedom of the $F$ criterion multiplied by the Huynh-Feldt factor E (0.845) as the Mauchly's sphericity test was statistically significant $\left[W=0.591 ; X^{2}(5)=35.63 p<0.001\right]$ (Girden, 1992).

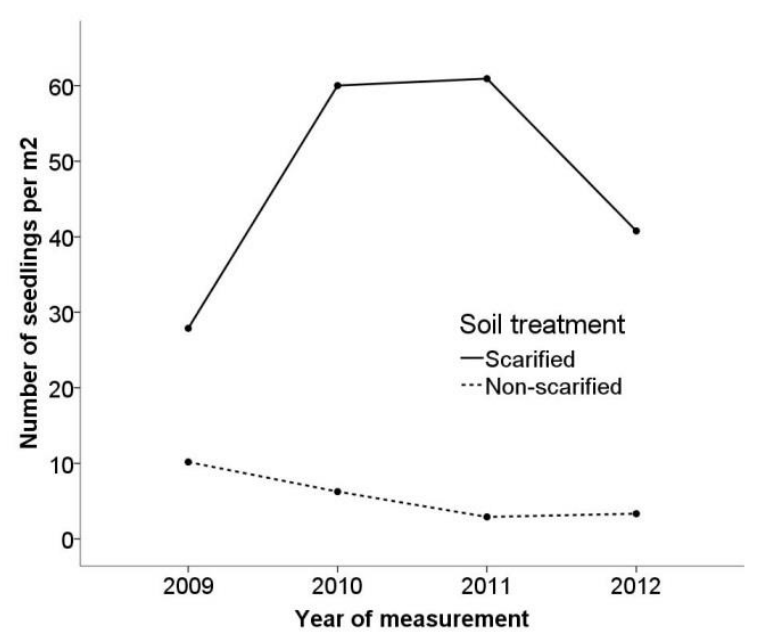

Figure 4. Effect of treatment and time of measurement in the mean values of live seedlings $\mathrm{m}^{-2}$

Taking into consideration the effect between subjects factor (replication), the number of live seedlings in the scarified soil follows the same as previous pattern in time compared to non-scarified soil. In scarified soil there was an increase in the regeneration measurements for the four years in all three replications. More specifically, in 2009 regeneration went up from 23 to 31 seedlings $\mathrm{m}-2$; in 2010 from 52 to 66 seedlings $\mathrm{m}^{-2}$; in 2011 from 51 to 77 seedlings $\mathrm{m}^{-2}$; and in 2012 from 33 to 48 seedlings $\mathrm{m}^{-2}$. Natural regeneration was less in non-scarified soil than in scarified with statistically significant differences in measurements for the four years (Table 2). More specifically, there was variation in natural regeneration in 2009 from 2 to 16 seedlings $\mathrm{m}^{-2}$, in 2010 from 2 to 9 seedlings $\mathrm{m}^{-2}$, and inn 2011 and 2012 from 1 to 4 seedlings $\mathrm{m}^{-2}$. 
Table 2. Distribution of Scots pine seedlings $\mathrm{m}^{-2}$ on scarified and non-scarified soil for the three replications (mean values)

\begin{tabular}{ccccccccccccc}
\hline & \multicolumn{3}{c}{ Repetition I } & \multicolumn{3}{c}{ Repetition II } & \multicolumn{3}{c}{ Repetition III } \\
\cline { 2 - 12 } & \multicolumn{3}{c}{ Scarified soil } & \multicolumn{1}{c}{ non-scarified } & \multicolumn{2}{c}{ Scarified soil } & non-scarified & \multicolumn{2}{c}{ Scarified soil } & non-scarified \\
\cline { 2 - 12 } & Live & Dead & Live & Dead & Live & Dead & Live & Dead & Live & Dead & Live & dead \\
\hline 2009 & $23^{* *}$ & 2 & $13^{* *}$ & 0 & $31^{* *}$ & 0 & $16^{* *}$ & 0 & $30^{* *}$ & 0 & $2^{* *}$ & 0 \\
\hline 2010 & $66^{* *}$ & 1 & $9^{* *}$ & 0 & $63^{* *}$ & 0 & $8^{* *}$ & 0 & $52^{* *}$ & 0 & $2^{* *}$ & 0 \\
\hline 2011 & $55^{* *}$ & 2 & $4^{* *}$ & 0 & $77^{* *}$ & 2 & $4^{* *}$ & 0 & $51^{* *}$ & 0 & $1^{* *}$ & 0 \\
\hline 2012 & $33^{* *}$ & 2 & $4^{* *}$ & 0 & $48^{* *}$ & 6 & $4^{* *}$ & 0 & $41^{* *}$ & 0 & $1^{* *}$ & 0 \\
\hline
\end{tabular}

** Denotes statistical significant differences at $a=0,05$ between scarified and non-scarified soil in the four years

Figure 5 shows that there are no significant differences among the three replications $F(2 ; 69)=2.75$; $p=0.071$, but there was significant interaction between time of measurement and replications $F(5.07$; 174.84)=3.48; $p<0.001$. In addition, it can be seen that the time of measurement $x$ soil treatment $x$ repetition interaction was significant $F(5.07 ; 174.84)=3,48 ; p<0.001$, depicted by the non-parallel curves in Figure 5. The values for the $\mathrm{F}$ criterion for the two and three way interactions resulted from the correction of the degrees of freedom of the $F$ criterion multiplied by the Huynh-Feldt factor $E(0.845)$ as the Mauchly's sphericity test was statistically significant $\left[W=0.591 ; X^{2} \quad(5)=35.63 ; p<0.001\right]$ (Girden, 1992).
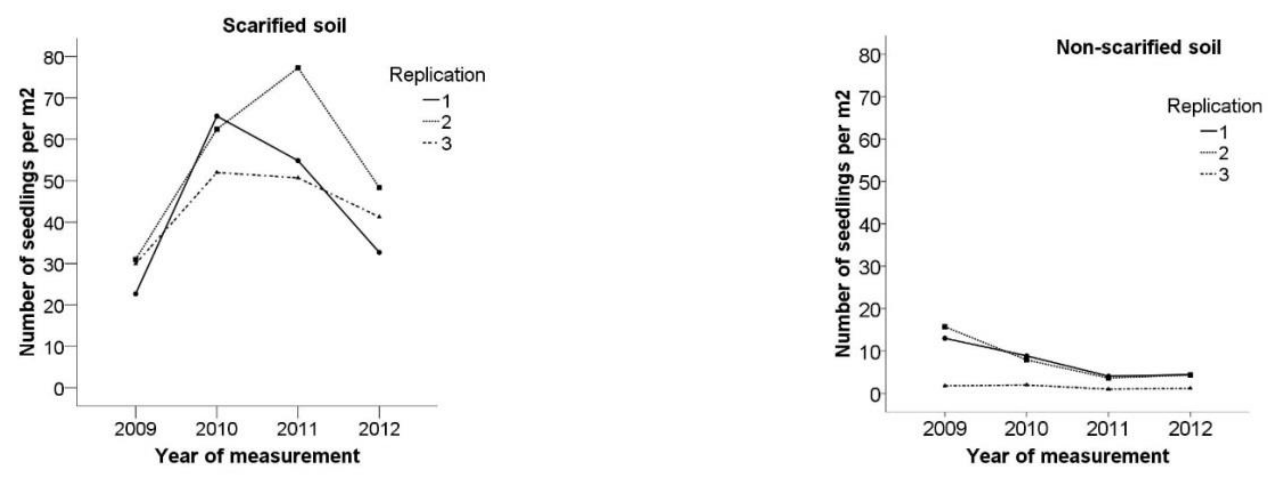

Figure 5. Effect of treatment, replication and time of measurement of live seedlings $\mathrm{m}^{-2}$ in mean values

\subsubsection{Dead seedlings}

The number of dead seedlings in scarified soil followed a different evolution pattern in time compared to non-scarified soil. More specifically, in Figure 6, in 2009 and 2010 there was less than $1 \mathrm{~m}^{-2}$ of dead seedlings in scarified soil and $0 \mathrm{~m}^{-2}$ in non-scarified. In 2011 and 2012, there were $3 \mathrm{~m}^{-2}$ of dead seedlings in scarified soil, while in non-scarified it remained the same at $0 \mathrm{~m}^{-2}$. There was a significant main effect of soil treatment on dead seedlings $[F(1 ; 69)=49.14 ; p<0.001]$. There was also a significant main effect of time of measurement on dead seedlings $[F(1.96 ; 135.32)=19.85 ; p<0.001]$. There was significant interaction between time of measurement and soil treatment $[F(1.96 ; 135.32)=18.79$; $p<0.001]$, indicated by the non-parallel lines in Figure 6 . The values for the $F$ criterion for the time effect but also for the time $x$ soil treatment interaction resulted from the correction of the degrees of freedom of the $F$ criterion multiplied by the Huynh-Feldt factor $E(0.654)$ as the Mauchly's sphericity test was statistically significant $\left[\mathrm{W}=0.144 ; \mathrm{X}^{2}(5)=131.38 \mathrm{p}<0.001\right]$. 


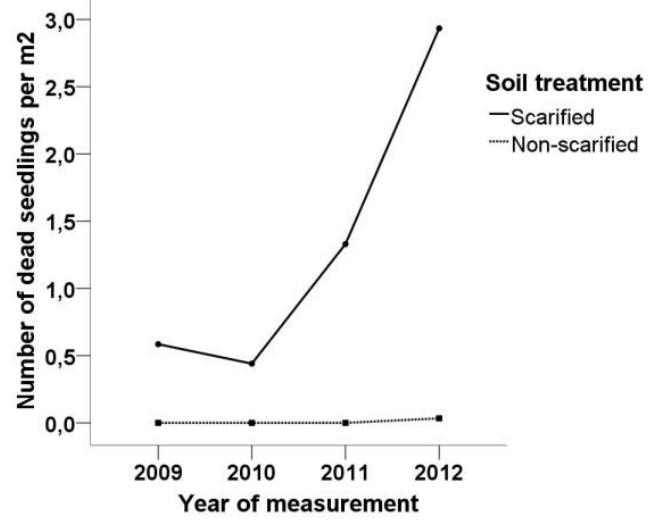

Figure 6. Effect of treatment and time of measurement of dead seedlings per $\mathrm{m}^{2}$ in mean values

It can be clearly seen in Figure 7 that there were no dead seedlings in the non-scarified soil in the time period of the study. However, the same figure shows that there was an increase in dead seeds in scarified soil in these four years. More specifically, in 2009 and 2010 the dead seedlings from $0 \mathrm{~m}^{-2}$ rose to $2 \mathrm{~m}^{-2}$ and $1 \mathrm{~m}^{-2}$ respectively; whereas in 2011 and 2012 from $0.5 \mathrm{~m}^{-2}$ they reached $6 \mathrm{~m}^{-2}$ and $5 \mathrm{~m}^{-2}$ respectively. These measurements were statistically significant for the entire time period. More specifically, there was a significant interaction effect among replications $[F(2 ; 69)=8.77 ; p<0.001]$, a double interaction effect of time of measurement and replications $[F(3.9 ; 135.32)=10.23 ; p<0.001]$ and a triple interaction effect among time of measurement, replications and soil treatment $[F(3.9$; $135 ., 32)=10.7 ; p<0,001]$. The values for the $F$ criterion for the time effect but also for the time $x$ soil treatment interaction resulted from the correction of the degrees of freedom of the $F$ criterion multiplied by the Huynh-Feldt factor E (0.654) as the Mauchly's sphericity test was statistically significant $\left[\mathrm{W}=0.144 ; \mathrm{X}^{2}(5)=131.38 \mathrm{p}<0.001\right]$.
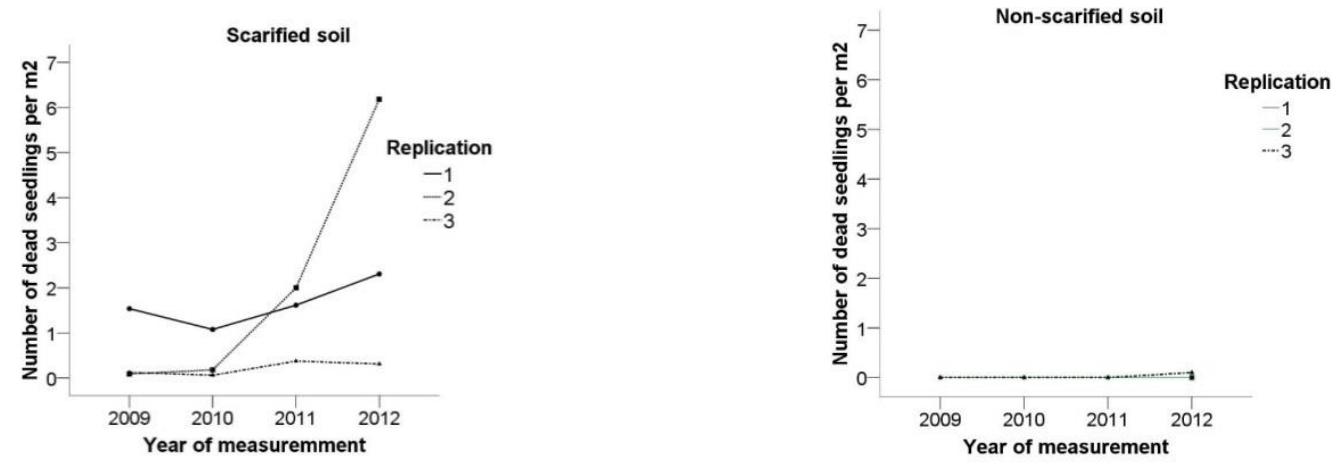

Figure 7. Effect of treatment, replication and time of measurement of dead seedlings $\mathrm{m}^{2}$ in mean values

The difference in evolution patterns in the number of dead seedlings is sharper in the second replication than in either the first or the third. The reason for this is due to the fact that there is less protection from the mother stand. The mean canopy closure in the three replications are $45 \%, 5 \%$ and $27 \%$ respectively.

\section{Discussion}

The Scots pine forest at the Sarakatsana location has a number of particular ecological and silvicultural characteristics, which make it warrant attention. These include: it is located in the southernmost limits of its geographic distribution in Europe, its structure which is one-storeyd, even aged and of low density; its critical health status because of dieback effects and the absence of natural regeneration. 
The old growth Scots pine forest at the Sarakatsa location in the Pieria Mountains is around 130 years old and although it has potential, there is an absence of regeneration for a couple of important reasons. Intensive grazing in the past and present and the thick-dense ground vegetation layer of Vaccinium myrtilus prevent natural regeneration.

These results from the large and statistically significant difference of living Scots pine seedlings between scarified and non-scarified soil but as well as from the regeneration observed on the sides of the forest roads.

The experimental area was fenced off to exclude livestock grazing, which is well-known to have been extensive in these forests for the past decades. Those that are not grazed present a small increment (Zamora et al., 1999). Significant seed losses have also been observed due to birds (Nystrand \& Granström, 1997). Fencing of the study area coupled with the application of soil treatment seem to have had a positive effect on the emergence, density and early evolution of natural regeneration.

Therefore, soil scarification is clearly favourable for the establishment of Scots pine, provided that it is carried out at the appropriate time of year, namely, early autumn in a full seed year prior to seedfall, as was the case in this study. The combination of soil treatment and favourable weather conditions resulted in two years of good seed production, which had the effect of the successful emergence and establishment of regeneration. The number of live seedlings after four measurements taken in four years in the scarified soil exhibit statistically significant differences between and within the main efects of subjects and their associated interactions. This can be explained by the different amount of seed production of the mother trees, the spatial position of the replications (relief, stand density) which received different amounts of seeds from side seed rain, and finally the weather conditions during the vegetation period from April to October (Figure 2). There was a gradual but marked decrease in the relative humidity during the vegetation period (April - October), which from $77.1 \%$ in 2009 fell to $74.1 \%$ in 2011 only to exhibit a further large drop to reach 64.4\% in 2012. In addition, during the vegetation period there was a large fluctuation in the mean monthly precipitation (Figure 3). In 2011, there was almost a $50 \%$ reduction in precipitation in comparison to the two previous years. This hot and dry period in 2011 was followed by autumn rainfalls that did not exceed $63 \mathrm{~mm}$.

After the successful emergence of the Scots pine natural regeneration in the first two years (Figure 5) and despite the fact that 2011 was a good seed production year in terms of the number of seeds prodused (Table 1 ) over half $(57,2 \%)$ of the disseminated seeds found to be empty after a laboratrory germination test. This meant that there were far fewer new seedlings in 2012, and which had an increased mortality due to the dry summer and autumn periods of the previous year. In the nonscarified soil, there was a progressive decrease in the number of live seedlings, which showed a different evolution pattern to those in scarified soil. The dry weather conditions in both 2010 and 2011 negatively affected the dead organic matter and ground vegetation of the soil surface which meant that the Scots pine seeds which had reached the forest floor were not able to develop enough root in order to penetrate the thick ground vegetation leyer and reach the mineral soil.

In the years 2010 and 2011, there was an increased number of dead seedlings, particularly in scarified soil (Figures $6 \&$ 7). In the non-scarified soil, dead seedlings were not measured as they were next to impossible to detect in such dense ground vegetation.

The small number of dead seedlings that was measured during the first two measurements may be due to favorable environment, in terms off good site, stand and weather conditions, which enchanched the seedlings regeneration emergence and survival. However it may also due to the difficult summer conditions preveling those two summers which may resulted in large number of seedling have been decaying and having disappearing until the next annual regeneration record.

There were similar findings in other comparable research. According to a study by Apatsidis (1977), soil treatment in the form of circular plots ensures favourable germination conditions for black pine seeds as well as the survival of a suficient number of seedlings. Zagas (1990), reports that in Scots pine stands, in the Rhodope Mountains, natural regeneration was possible for all site qualities with the exception of those found at the lowest site quality, provided that all the appropriate silvicultural treatments were 
applied, such as the removal of ground vegetation. In their study on black pine stands Vergos et al., (1994) reported that the establishment and survival of natural regeneration in aged and poor site quality black pine stands was significantly enchanced by soil that had undergone some kind of treatment.

González-Martínez and Bravo, (2001) in their work on the density and structure of natural regeneration of Scots pine in the high basin of the Ebro River report that the ground vegetation is the natural barrier that prevents the Scots pine seeds to come into contact with the mineral soil and creates strong competition with the seedlings, also grazing changes the vegetation composition and has a negative impact on the establishment and development of seedlings. They conclude that fencing of stands under regeneration is the only reliable long-term measure to ensure the development of natural regeneration. Moreover, in their study on the regeneration of Scots pine, Béland et al., (2000) found that after four years in low-intensity shelterwood cut (mother stand with 200 stems $^{-1}{ }^{-1}$ ) in scarified soil, there were more than $80,000 \mathrm{ha}^{-1}$ seedlings, there in clear cut and scarified soil up to 7,000 seedlings ha ${ }^{-1}$ were found. They also referred to the important role that the mother stand plays in the number of seeds reaching the forest floor. Thus, the denser the mother stand, the greater the number of seeds that reach the scarified soil. There is also a smaller invasion of the competitive ground vegetation, resulting in prolonged regeneration and small mortality of seedlings.

\section{Conclusions}

The conclusions that can be drawn from this study are: The condition of the mother stand is critical in terms of helth status, but fortunately there is still considerable regeneration potential such as the number of parent trees and fruiting capacity. All Scots pine stands in the Pieria mountains with these specific structural characteristics should be progressively fenced and regenerated by the shelterwood method, combined with soil scarification. It is important to carry out the soil trteatment in autumn, after a full seed year and when weather conditions are favourable.

\section{Acknowledgements}

The authors are grateful to the Forest Directorate of Pieria for providing all the necessary support for the impementation of this study, also to George Roupakias for his hard work in the field.

\section{References}

Apatsidis L. (1977), Black pine natural regeneration. Search of suitable regeneration methods in relation to the site - ecological conditions. [dissertation]. Thessaloniki (GR): Aristotle University.

Athanasiadis N. (1986), Forest Botany (Trees and Shrubs of Greek forests) part II. Giachoudis - Giapoulis: Thessaloniki (GR).

Béland M., Agestam E., Ekö P.M., Gemmel P. and Nilsson U. (2000), Scarification and Seed fall affects Natural Regeneration of Scots Pine under Two Shelter wood Densities and a Clear-cut in Southern Sweden, Scandinavian Journal of Forest Research, 15, $247-255$.

Bergengren J.C., Waliser, D.E. and Yung, Y.L. (2011), Ecological sensitivity: A biospheric view of climate change, Climatic Change, 107, 433-457.

Castro J., Zamora R. and Hódar J.A. (2002), Mechanisms blocking Pinus sylvestis colonization of Mediterranean mountain meadows, Journal of vegetation science, 13, 725-731.

Castro J., Zamora R. Hódar J.A. and Gómez J. (2004), Seedling establishment of a boreal tree species (Pinus sylvestris) at its southernmost distribution limit: consequences of being in a marginal Mediterranean habitat, Journal of Ecology, 92, 266- 277

Diamandis S. and de Kam M. (1986), A severe attack on scots pine by the resin top disease in N. Greece, European Journal of Forest Pathology, 16, 247-249.

Diamandis S. and Perlerou Ch. (2003), Management of a severe attack of Peridermium pini on Pinus sylvestris in its southernmost limit of extension in Europe. Proceedings of 2nd International Conference on rusts of forest trees, Xian, China, 19-24 August 2002, Forest research, 16,113-117. 
Dohrenbusch A. (1997), The natural regeneration of Scots pine (Pinus silvestris L.), Series of University of Göttingen and of Forest Research Institute of Niedersachsen Band 123, p.269) (In German)

Girden E.R. (1992), ANOVA: repeated measures. Sage University Papers Series on Quantitative Applications in the Social Sciences, 84. Thousand Oaks, CA: Sage.

González-Martínez S.C. and Bravo F. (2001), Density and population structure of the natural regeneration of Scots pine (Pinus sylvestris L.) in the High Ebro Basin (Northern Spain), Annals of Forest Science, 58, 277-288.

Grace J., Berninger F. and Nagy L. (2002), Impacts of climate change on the tree line, Annals of Botany, 90, 537-544.

Groffman P.M., Driscol Ch.T., Johnson Ch.E., Rustad L.E. and Templer P.H. (2012), Long-Term Integrated Studies Show Complex and Surprising Effects of Climate Change in the Northern Hardwood Forest, BioScience, 62, 1056-1066.

Hallikainen V., Hyppönen M., Hyvönen J. and Niemelä J. (2007), Establishment and height development of harvested and naturally regenerated Scots pine near the timberline in North-East Finnish Lapland, Silva Fennica, 41(1), 71-88.

Hannerz M., Alqmqvist C. and Hörnfeldt R. (2002), Timing of seed dispersal in Pinus sylvestris stands in Central Sweden, Silva Fennica, 36 (4), 757-765.

Hille M. and Ouden J. (2004), Improved recruitment and early growth of Scots pine (Pinus sylvestris L.) seedlings after fire and soil scarification, European Journal of Forest Research, 123, 213-218.

Huss, J. and Burschel, P. 1972. Promoting natural regeneration of Beech with various soil cultivation techniques. Results of prolonged observations, Forstarchiv, 43, 233-239, (In German with English summary).

Karlsson Ch. and Örlander G. (2000), Soil scarification shortly before a rich seed fall improves seedling establishment in seed tree stands of Pinus sylvestris, Scandinavian Journal of Forest Research, 15, 256 - 266.

Koski V. (1991), Genetics of Scots pine. Akadémiai Kiadó: Budapest, (HU). Generative reproduction and genetic processes in nature; p. 59-72.

Kullman L. (2007), Tree line population monitoring of Pinus sylvestris in the Swedish Scades, 1973-2005: implications for the tree line theory and climate change, Journal of Ecology, 95, 41-52.

Kuuluvainen T. and Rouvinen S. (2000), Post-fire under storey regeneration in boreal Pinus sy/vestris forest sites with different fire histories, Journal of Vegetation Science, 11, 801-812.

Loarie R.S., Duffy Ph.B., Hamilton H., Asner G.P., Field Ch.B. and Ackerly D.D. (2009), The velocity of climate change, Nature, 462, 1052-1055.

Mason W.L. and Alia R. (2000), Current and future status of Scots pine (Pinus sylvestris L.) forests in Europe. Investigación Agraria: Sistemas y Recursos Forestales, 15 (1-2): 317-335.

MEDDMAN, live meteorological station. Laboratory of General and Agricultural Hydraulics and Land Reclamation. Faculty of Agriculture, Aristotle University of Thessaloniki, http://meddman.agro. auth.gr/index.php?stationID=7 (last access: 15 April 2014).

Ministry of Agriculture. (1992), Results of the first national forests inventory. General secretariat of forests and natural environment. Directorate of forest cadaster, inventory and forests classification: Athens (GR).

Nystrand O. and Granström A. (1997), Post-dispersal predation on Pinus sylvestris seeds by Fringilla spp: ground substrate affects selection for seed colour, Oecologia, 110: 353-359.

Page M.C., Braver S.L. and Mackinnon D.P. (2003), Levine's Guide to SPSS for Analysis of Variance, second edition. Lawrence Erlbaum Associates, Inc: New York (US)

Papamichos N. (1979), Implementation of a specially developed system for the rapid determination, description and mapping of mountainous soils (Pieria district). Ministry of Agriculture, General directorate of forests and forestry environment, Directorate of programing and development, Department of inventory, mapping and forest soils classification: Athens (GR).

Rebetez M. and Dobbertin M. (2004), Climate change may already threaten Scots pine stands in the Swiss Alps, Theoretical Applied Climatology, 79, 1-9.

Rodrigo A., Retana J. and Xavier Picó F. (2004), Direct regeneration is not the only response of Mediterranean forests to large fires, Ecology, 85, 716-729.

Strid A. and Tan K. (1997), Flora Hellenica Vol. 1, Koeltz Scientific Books: Königstein (DE). 
Tegelmark D.O. (1998), Site factors as multivariate predictors of the success of natural regeneration in Scots pine forests, Forest Ecology and Management, 109, 231-239.

Vergos S., Xystras D. and Chatziphilippidis G. (1994), Establishment and evolution of natural regeneration in degraded black pine stands. Technological Educational College of Larisa, Department of Forestry.

Zagas Th. (1990), Conditions of Scots pine natural regeneration in Rhodope [disertation]. Thessaloniki (GR): Aristotle University.

Zamora R., Hódar J.A. and Gómez J.M. (1999). Plant herbivore interaction: beyond a binary vision. In: Pugnaire F. I. and Valladares F. (eds). Handbook of functional plant ecology. Marcel Dekker Inc, pp. 677- 718. 